\title{
DA NECESSIDADE DE UMA UNIVERSALIDADE REDIVIVA PARA OS DIREITOS HUMANOS
}

\author{
OF A UNIVERSAL NEED RESURRECTED FOR HUMAN RIGHTS
}

Leandro Caletti

Mestrando no Programa de Mestrado Acadêmico em Direito da Faculdade Meridional (IMED). Membro do Grupo de Pesquisa "Transnacionalismo e Circulação de Modelos Jurídicos". Bolsista PROSUP/CAPES vinculado ao PPGD-IMED.

E-mail: cttlers@gmail.com

Márcio Ricardo Staffen

Doutor em Direito Público pela Università degli Studi di Perugia (Itália). Doutor e Mestre em Ciência Jurídica pela Universidade do Vale do Itajaí - UNIVALI. Pesquisador do Conselho Nacional de Justiça (CNJ). Coordenador do Programa de Pós-Graduação Stricto Sensu em Direito - IMED, Passo Fundo/RS. Professor Honorário da Faculdade de Direito e Ciências Sociais da Universidad Inca Garcilaso de la Vega (Peru).

E-mail: marcio.staffen@imed.edu.br

Recebido em: 08/09/2016

Aprovado em: 17/11/2016

Doi: $10.5585 /$ rdb.v16i7.475

\begin{abstract}
RESUMO: A compreensão segundo a qual os Direitos Humanos são universais e inerentes à pessoa, independentemente de quaisquer outras circunstâncias ou características, inaugurada nos primórdios do cristianismo e adotada pela Organização das Nações Unidas, reforça a exclusão da principal nota componente do ideal de Direitos Humanos, a saber, o Humanismo. Nesse cenário, têm espaço críticas relativistas cada vez mais ácidas e ressonantes, as quais colocam em xeque a procedência e a utilidade do tão propalado e festejado argumento universalista (e, por consequência, dos próprios Direitos Humanos). O problema de pesquisa, nesse norte, se constitui em aferir se a predita universalidade dos Direitos Humanos se constitui em meio eficaz à proteção efetiva da dignidade das pessoas em todos os pontos do orbe terrestre. Para tanto, valese da dedução como método e da pesquisa bibliográfica como técnica, antecipando, desde agora, a conclusão pela necessidade de um critério universal atualizado, dialógico e multicultural.
\end{abstract}

Palavras-chave: Direitos Humanos; Humanismo; Universalismo.

ABSTRACT: Understanding according to which Human Rights are universal and inherent to the person, regardless of any other circumstances, inaugurated in early Christianity and adopted by the United Nations, reinforces the exclusion of the main component note ideal of Human Rights, namely Humanism. In this scenario, they have critical space relativistic increasingly acidic and resonant, which call into question the validity and usefulness of the heralded and celebrated Universalist argument (and, therefore, the own Human Rights). The research problem, in this north, constitutes assess whether the predicted universality of Human Rights constitutes an effective means for the effective protection of the dignity of people in all parts of the terrestrial 
globe. Therefore, it is the deduction as a method and literature as a technique, anticipation, since now, the conclusion by the need for an updated universal criterion, dialogical and multicultural.

Keywords: Human Rights; Humanism; Universalism.

SUMÁRIO: Introdução; 1. O processo jurídico-histórico de formação do ideal de direitos humanos; 2. A universalidade abstrata e racional da Declaração Universal dos Direitos Humanos; Conclusão; Referências.

\section{INTRODUÇÃO}

Embrenhar-se no estudo dos Direitos Humanos ${ }^{1}$ implica, já a priori, em aquiescer com alguns respingos de experiências que atingiram exatamente o ápice do oposto: a indignidade. Trata-se, realmente, de uma inexorabilidade tal a que não permite a autodefinição ausente o paradigma $^{2}$ do estranho. Isto é assim, explica Edgar Morin (2007, p. 77), porque apenas a oposição do Outro deflagra a comparação capaz de identificar. Não há interação humana, com efeito, se o Outro $^{3}$ não é reconhecido como pessoa, mas tão somente como objeto.

A primeira metade do século XX foi pródiga em exemplos que tais: o surgimento, o aumento de poder e as atrocidades das chamadas sociedades totalitárias - fascismo, nazismo, stalinismo - desvelou um cenário em que o Direito, enquanto meio de controle social, não se sustentou como anteparo à dignidade. Essa inferência subsidiou, no Segundo pós-Guerra, o surgimento da Organização das Nações Unidas e a eleição, por esta última, do critério

\footnotetext{
1 "Sólo son derechos [Humanos] aquellos que se pueden justificar racionalmente como pretensiones morales iguales para todos los hombres y para todos los tiempos, y son previos al contrato y al consenso que lo produce. En realidad, tras esta presentación objetiva y racional se esconden unas exigencias históricas y unos intereses sentidos por la burguesía, que es quien impulsa el proceso con el objetivo de limitar el poder político. Cada derecho, desde la libertad de conciencia y de pensamiento a las garantías procesales que se justifican con razones abstractas, aparecen como exigencias de la realidad del mundo moderno y será necesaria esa coyuntura para su toma de conciencia y su formulación". (PECES-BARBA MARTÍNEZ, 1995, p. 200).

${ }^{2}$ Sempre que se faz referência a essa categoria, é inexorável trazer à baila o conceito operacional de quem primeiro a cunhou: "paradigmas são as realizações cientificas universalmente reconhecidas que, durante algum tempo, fornece problemas e soluções modelares para uma comunidade de praticantes de uma ciência". (KUHN, 1991, p. 13). Todavia, a compreensão do termo, neste ensaio, não segue a definição kuhniana, ostentando o sentido de modelo.

3 “1. Em Platão, o outro é, por oposição ao mesmo, o diverso, o múltiplo. 2. Enquanto oposto ao eu e ao nós, o outro constitui um conceito fundamental e primeiro do pensamento: "Para obter uma verdade qualquer sobre mim, devo passar pelo outro. O outro é indispensável à minha existência, tanto quanto à consciência que tenho de mim" (Sartre). Nesse sentido, o outro é uma espécie de alter ego que, de certa forma, construímos intelectualmente, não sendo compreendido como outro, em sua diferença; segundo a fórmula de Sartre, "nós encontramos o outro, não o constituímos". 3. Na teoria hegeliana da intersubjetividade, o problema do outro opõe-se à filosofia cartesiana do cogito. A intersubjetividade é a mediação necessária ao advento da consciência de si. E o que mostra a "dialética do senhor e do escravo": ela descreve a passagem da consciência mergulhada na vida orgânica imediata ao estado de uma consciência que "se realizou" como consciência de si, porque seu desejo se tornou desejo de outro desejo. Desejo de um outro desejo, quer dizer, para a consciência, desejo de ser reconhecida como tal por uma outra consciência. 4. Esse pensamento hegeliano da intersubjetividade é o ponto de partida da reflexão fenomenológica. A partir de Husserl, os fenomenólogos exploram o campo da "descoberta do outro enquanto outro" e tentam mostrar o que há de irredutível na experiência do outro: seu estatuto não é o de um objeto, mesmo "habita-do" por uma consciência. Na mesma linha hegeliana, a psicanálise lacaniana afirma que "o desejo do homem é o desejo do outro". Essa fórmula, que retoma a dialética do senhor e do escravo, mostra que o inconsciente não é nem individual, nem coletivo, nem transindividual". (JAPIASSÚ; MARCONDES, 2001, p. 145). Este estudo adota, para a categoria, a concepção fenomenológica de Emmanuel Lévinas (1980, p. 192): “[...] a não coincidência consiste, concretamente, na minha posição como irmão, implica outras unicidades em torno de mim, de maneira que a minha unicidade de mim resume ao mesmo tempo a suficiência do ser e a minha parcialidade, a minha posição em face do outro como rosto. No acolhimento do rosto (acolhimento que é já minha responsabilidade a seu respeito e em que, por consequência, ele me aborda a partir de uma dimensão de altura e me domina), instaura-se a igualdade".
}

Revista de Direito Brasileira | São Paulo, SP | v. 16 | n. 7 | p. 96 - 114 | Jan./Abr. 2017 
universalista dos direitos decorrentes de sua Declaração Universal dos Direitos Humanos, premissa essa originalmente oriunda das primeiras incursões do pensamento judaico-cristão.

Os Direitos Humanos, nessa temática, absorveram os influxos desse universalismo de pretensões ocidentais e homogeneizadoras, fato que lhe catapultou, no momento presente, à oposição desafiadora dos multiculturalismos e das críticas da doutrina relativista cultural. Por consequência, a lógica que tem regido a interpretação em torno desses direitos e que, igualmente, é consequência clara do universalismo abstrato, projeta uma crise de extensas proporções, que afeta em cheio o ideal de Direitos Humanos. Em vista disso, afigura-se pertinente uma reformulação da lógica aplicativa dos Direitos Humanos, passando-se da noção dual e estanque que amplifica a eterna dicotomia entre universalistas e relativistas culturais, para uma visão dialógica e multicultural que inclua o reconhecimento do Outro, consolidando experiências sociais, econômicas, políticas, religiosas etc. Essa consolidação, necessária e já intempestiva, resgataria qualidades humanas atualmente esquecidas, cujo reconhecimento universal pode surgir como ponto de equilíbrio das civilizações.

A partir dessas premissas, este artigo utiliza o método dedutivo ${ }^{4}$, cuja premissa maior é a reavaliação do critério universalista dos Direitos Humanos, objetivando reconstruir também a lógica aplicativa dessa universalidade para uma visão dialógica e multicultural (premissa menor). A técnica utilizada é a pesquisa bibliográfica ${ }^{5}$. O problema de pesquisa, nesse norte, se constitui em aferir se a predita universalidade dos Direitos Humanos, originada na doutrina da incorruptibilidade do homem, propugnada pelo apóstolo Paulo, tal qual formulada na Declaração Universal dos Direitos Humanos, se constitui em meio eficaz à proteção efetiva da dignidade das pessoas em todos os pontos do orbe terrestre. A hipótese para esse questionamento exsurge negativa, delegando à atualização e à reconstrução do critério universalista o desiderato predito, a partir da reinserção do Humanismo $^{6}$ e da consideração de uma concepção multicultural desses últimos.

O objetivo geral, assim, é o de reexaminar o critério universalista dos Direitos Humanos, reconstruindo-o a partir da reinserção do Humanismo e da consideração de uma concepção multicultural dos primeiros. Os objetivos específicos se estratificam em: 1) revisitar o processo jurídico-histórico de formação do ideal de Direitos Humanos, com ênfase no Humanismo; 2) delinear a assunção do critério universalista a partir da criação da Organização das Nações Unidas; 3) propor a reconstrução do ideal universalista a partir da reinclusão do Humanismo e da consideração de uma concepção multicultural dos Direitos Humanos. Os constructos teóricos deste artigo podem ser expressados pelos pensamentos de autores como Gregorio Peces-Barba Martínez, Joaquín Herrera Flores, Antonio Enrique Pérez-Luño, Antonio Cassese, Stefano Rodotà, entre outras leituras inerentes à delimitação temática.

\section{O PROCESSO JURÍDICO-HISTÓRICO DE FORMAÇÃO DO IDEAL DE DIREITOS HUMANOS}

\footnotetext{
4 “[...] base lógica da dinâmica da Pesquisa Científica que consiste em estabelecer uma formulação geral e, em seguida, buscar as partes do fenômeno de modo a sustentar a formulação geral". (PASOLD, 2011, p. 205).

5 “[...] Técnica de investigação em livros, repertórios jurisprudenciais e coletâneas legais”. (PASOLD, 2011, p. 207).

${ }^{6}$ Esta categoria suscita definições as mais diversas, conforme se escolha a nuança filosófica, antropológica ou jurídica. Para o presente estudo, o norte filosófico é colhido de Pedro Dalle Nogare (1994, p. 15): “[...] Em sentido lato, este humanismo filosófico pode significar qualquer conjunto de princípios doutrinais referentes à origem, natureza, destino do homem. [...] Em sentido estrito, o humanismo filosófico é qualquer doutrina que em seu conjunto dignifica o homem”. Na acepção jurídica, adota-se a conceituação de David Sánchez Rubio (2010, p. 15): "[...] uma sinergia dotada de força sinestésica que se realiza na complexidade, nas relações intersubjetivas, de forma não-hegemonizada. Para tanto, o colecionamento destes argumentos supera a visão reducionista consubstanciada nos dogmas jurídicos-estatais dos Direitos Humanos, forte apenas em glossários técnicos obsoletos".
} 
A crise atravessada pelos Direitos Humanos é produto do afastamento do Humanismo em detrimento de um discurso de institucionalização estatal e burocrática desses direitos, mormente por meio de "um universalismo abstrato, que tem no mínimo ético um ponto de partida e não de chegada", adverte Flávia Piovesan (2009, p. 13).

A procura e a construção de uma nova base para o critério universalista prescindem, nessa temática, do retorno à origem de formação do ideal de Direitos Humanos, o qual, por sua vez, requer um resgate histórico que remonta ao medievo e às primeiras manifestações do direito natural (só se poderá falar em Direitos Humanos ou direitos fundamentais a partir da Modernidade $^{7}$ ), o que se passa a fazer.

É assente de dúvidas que a cultura dos Direitos Humanos e, por conseguinte, a linguagem que o propala se inclina a uma visão subjetiva, a referências individuais e à titularidade dos direitos, mais do que com o sistema de normas que o sustenta e ampara, de modo a que o sujeito e a sua proteção constituam o núcleo central necessário para a compreensão do problema e os elementos unificadores últimos, que se comunicam a todas as expressões sinônimas a Direitos Humanos. Ter-se-ia, nessa intelecção, a dimensão tríade formulada por Peces-Barba Martínez (1995, p. 23), estratificada assim: $1^{\text {a }}$ ) uma pretensão moral justificada (liberdade, dignidade da pessoa, igualdade); $2^{a}$ ) a real pretensão de se converter em norma positiva (que lhe preveja também a respectiva garantia); e $3^{\text {a }}$ ) conformidade com a realidade social.

O ideal de Direitos Humanos nasce, nessa conformidade, integrado pela noção de proteção à pessoa enquanto ser humano e pelo pressuposto de dignidade. Importa pontuar, desde agora, que esse ideal não é fechado, imóvel e composto de um único caractere. Ele adveio com essa premissa dignitária do ser, todavia, na sua gênese, é poroso a outras demandas que, ao longo do tempo, pela conformação do momento histórico, lhe vão sendo atraídas.

Se é bem verdade que os debates de Bartolomé de las Casas sobre a questão do reconhecimento do índio como ser humano contiveram clara noção humanista, foram a negação da Hegemonia da Santa Sé e a liberdade religiosa, em verdade, que constituíram o rompimento com o direito natural divino, num período denominado Trânsito à Modernidade ${ }^{8}$. É neste espaço de tempo que a sociedade sofre transformações, mormente sociais, políticas e econômicas, que determinam o início da construção do ideal de Direitos Humanos. No âmago dessas modificações é que se visualizou o signo distintivo da construção do ideal de Direitos Humanos, a saber, o Humanismo.

Já se escreveu neste artigo que os Direitos Humanos surgiram, inicialmente, como direitos naturais de origem divina, no que se constituíam verdadeira Razão Instrumental ${ }^{9}$ da manutenção do status quo desejado, principalmente, pela Igreja Católica. Foi por razões como essa - uso da religião, conjugada e aparelhada no Direito, como instrumento de governo - que se desencadeou um processo de ruptura da mentalidade jurídica da época, culminando com a separação do direito da moral e a extirpação do cunho religioso do então direito natural: a Secularização ${ }^{10}$.

\footnotetext{
${ }^{7}$ Segundo a Filosofia, compreende a oposição ao movimento clássico, na qual há a libertação da pessoa daqueles valores tradicionais, da ignorância, engendrados por meio da racionalidade científica e pela ideia de progresso. (JAPIASSÚ; MARCONDES, 1996, p. 185).

${ }^{8}$ Designa o período que se inicia no século XIV e se estende até o século XVIII, no qual, de forma paulatina, a sociedade produz e sofre transformações que se constituem na sementeira do surgimento do ideal de Direitos Humanos, do primeiro direito humano fundamental e do próprio modernismo. (PECES-BARBA MARTÍNEZ, 1995, p. 115-116).

${ }^{9}$ No dizer de Charles Taylor (2009, p. 20, grifo do autor), um “[...] tipo de racionalidade a que recorremos quando ponderamos a aplicação dos meios mais simples para chegar a um dado fim. A máxima eficiência, a melhor ratio custo-produção, é a medida do sucesso".

${ }^{10}$ A secularização pressupõe mundanizar, extrair o cunho religioso da cultura, ao efeito de uma progressiva soberania da razão e de um protagonismo do homem orientado na direção de um tipo de vida puramente terrenal, em

Revista de Direito Brasileira | São Paulo, SP | v. 16 | n. 7 | p. 96 - 114 | Jan./Abr. 2017
} 
Uma nova mentalidade, impulsionada pelo humanismo e pela Reforma, se caracterizará pelo individualismo, o racionalismo e o processo de secularização. Em concreto, a Reforma protestante, com a ruptura da unidade eclesial, gerará o pluralismo religioso e a necessidade de uma fórmula jurídica que evite as guerras por motivos religiosos. Neste espaço, a tolerância, precursora da liberdade religiosa, será o primeiro direito fundamental. (GARCIA, 2005, p. 421).

Como aponta com propriedade Antonio Enrique Pérez-Luño (1979, p. 17), o ideal de Direitos Humanos tem como antecedente imediato a noção dos direitos naturais em sua elaboração doutrinal pelo iusracionalismo naturalista, que, imbricado com o Iluminismo (iusracionalismo iluminista), se constituiu no húmus para as revoluções americana e francesa, de onde também defluíram as primeiras declarações de direitos e as incipientes positivações.

Os preditos processos revolucionários tiveram a clara influência da construção filosófica contratualista, sendo por esse motivo que, na sociedade política emergente, os direitos naturais restaram transferidos ao poder absoluto do Estado, deixando a liberdade de ser individual para atrelar-se ao corpo político (só se mantinha no espaço privado insubordinado ao poder da lei, o da satisfação das necessidades).

A Revolução Americana, com efeito, ainda que tenha influenciado decisivamente a Francesa, incorporou muito menos do ideal de Direitos Humanos produzido no alhures examinado Trânsito à Modernidade que essa última. Isso tem um motivo bem claro: a insurreição das Treze Colônias aspirava o nascimento de um Estado independente, ao passo que a francesa foi arquitetada para se constituir numa ruptura com o antigo regime, em verdadeira situação revolucionária.

Noutro giro, a Revolução Francesa liberta o indivíduo do controle religioso, constituindo-se em verdadeiro processo revolucionário laico ou ateísta ${ }^{11}$. As declarações de direitos decorrentes desses processos revolucionários, especialmente a de 1789, a Constituição francesa de 1791 e o Código de Napoleão de 1804 deflagram a sementeira do moderno constitucionalismo (vinculação dos direitos a uma Constituição), da igualdade formal, da soberania e da separação dos poderes, a para de inaugurarem a concepção individualista da sociedade, embrião da futura democracia moderna, na intelecção de Norberto Bobbio (2004, p. $51)$.

Seja como for, importa concentrar a atenção no ápice do resgate jurídico e histórico proposto: o surgimento e o desenvolvimento dos ideais de Humanismo, frutos da efervescência e da difusão cultural do Renascimento. Na lição de Jorn Rusen e Oliver Kozlarek (2009, p. 11), o Humanismo representou o redirecionamento do centro de atenção ao pensamento e à ação dos seres humanos, postulado pelo qual a dinâmica dos acontecimentos alimenta uma espiral infinita que afirma a perene abertura e inconclusão dos projetos.

oposição à ordem da revelação e da fé, baseado na autoridade da Igreja. É consequência da ruptura da unidade religiosa, e abarcará a todas os seguimentos da vida, desde a arte, a pintura, a literatura, a nova ciência e a política a partir da obra de Maquiavel. Os temas religiosos são substituídos pelos problemas humanos. Em todo esse processo os direitos fundamentais realizarão progressivamente uma tarefa de substituição da ordem medieval, desde o momento em que supõe uma garantia de segurança que o edifício medieval, culminado por Deus, já não podia proporcionar; e que havia que encontrar nos homens mesmos. Na sociedade, progressivamente secularizada se poderá dar releve as necessidades da burguesia para a procura de uma nova ordem baseada na razão e na natureza humana; a ordem do individualismo e dos direitos naturais. (PECES-BARBA MARTÍNEZ, 2005, p. 81-82). Concepção de outro matiz pode ser encontrada em Jürgen Habermas (2007, p. 25-26): “[...] pretendo propor que a secularização cultural e social seja entendida como um processo de aprendizagem dupla que obriga tanto as tradições do Iluminismo quanto as doutrinas religiosas a refletirem sobre seus respectivos limites".

11 Não se ignora, no entanto, que o cristianismo evangélico teria papel de destaque, a posteriori, na "revolução dentro da "revolução burguesa", como se pode conferir em Ignasi Terradas Saborit (2009, p. 2).

Revista de Direito Brasileira | São Paulo, SP | v. 16 | n. 7 | p. 96 - 114 | Jan./Abr. 2017 
Com efeito, uma das principais características do Humanismo, nesse contexto, foi o de se separar da noção então vigente de vida como bem-aventurança a ser alcançada numa vida futura - que, por sua vez, só viria mediante o recitar de todos os dogmas e rituais impostos. Ao contrário, a visão humanista advoga exatamente a valorização da vida quotidiana, prática, de atividades mundanas e até mesmo da entrega a algum prazer. Há, no Humanismo, a pressuposição de que o homem é o centro da vida, considerado na sua grandeza, mas também consciente de suas limitações e fragilidades. Caros, aqui, são os sentimentos de livre pensamento e liberdade, numa concepção de ciência da dignidade do humano.

A tiracolo do humanismo, se descortina a filosofia spinoziana, responsável pela ruptura com o pensamento escolástico que instrumentalizara, no baixo medievo, uma ordem servil de submissão do Direito e da vida à "Deus" e aos seus desígnios seletivamente revelados, cuja utilidade única era a difusão de um temor esterilizante e supersticioso que, por meio de uma estrutura teológica, mantinha os privilégios e as condições de uma oligarquia baseada no sangue, no parentesco e na riqueza. Ao advogar um pensamento que propugna a imanência entre Deus e a Natureza, Spinoza descortina uma nova ideia da felicidade e da liberdade, inéditas no pensamento moderno.

De fato, em se podendo dividir a história da filosofia em dois grandes blocos, a saber, pensamento clássico (antigo e medieval) e pensamento moderno, o primeiro certamente foi inaugurado por Platão, podendo ser caracterizado pela filosofia da transcendência; o segundo, encontra em Spinoza o seu modelo: é a filosofia da imanência ou o racionalismo absoluto. Por isso é que a filosofia spinoziana se consubstancia numa ruptura ${ }^{12}$ entre a liberdade de pensamento, de expressão e de ação e a servidão ética, política e teológica que ainda reinava sob os influxos do tomismo ${ }^{13}$. Considerando que a obra do homem manifesta o exercício de seu pensamento e de sua liberdade, Santo Tomás recebeu de Aristóteles a concepção da excelência da política, reconstruindo a experiência grega sobre as bases da metafísica e das virtudes, pretendendo conciliar razão e fé. Essa reconciliação, que afetava todos os setores da vida, acabou por sustentar - ainda que de forma involuntária - uma ordem servil de submissão do Direito Natural e da vida à "Deus" e aos seus desígnios seletivamente revelados, cuja utilidade única era a difusão de um temor esterilizante e supersticioso que mantinha os privilégios e as condições de uma oligarquia baseada no sangue, no parentesco e na riqueza, sistema que perpetuava, a título de estratégia de manutenção do status quo, na política, na vida privada, na filosofia e na religião o irracionalismo e a superstição, decorrentes da exploração do medo e da esperança.

De onde nasce a superstição que leva ao irracionalismo? Do medo de males futuros ou de que bens não aconteçam, mas também da esperança de bens futuros ou de que males não aconteçam. Tanto o medo como a esperança exprimem a maneira confusa e inadequada com que a nossa imaginação conhecimento por meio de imagens que representam confusamente as coisas -, incapaz de compreender as leis necessárias que regem o universo e as ações

12 Este estudo não ignora que a filosofia spinoziana tenha levada a cabo outras fraturas, como a da dualidade cartesiana entre corpo e alma (Spinoza nega a afirmação de Descartes segundo a qual o corpo e a alma sejam substâncias diversas; para ele, alma, corpo e homem se constituem em modificações ou expressões singulares da atividade imanente de uma única e infinita substância). Igualmente, não se descura de que suas principais objeções tenham se destinado ora a Descartes, ora a Leibniz. O foco pela oposição à filosofia tomista se justifica pela delimitação temática do estudo.

13 Derivada da obra mais importante de Tomás de Aquino (Suma teológica), a tradição tomista é, inicialmente, consagrada à explicação da teologia católica. Sua argumentação, todavia, se difundiu tanto no plano filosófico quanto no teológico, recorrendo tanto a Aristóteles e aos filósofos clássicos quanto à Bíblia e aos Pais da Igreja. O tomismo se desenvolve, assim, dentro da filosofia escolástica, baseada nas disputas públicas ocorridas dentro das "escolas" de teologia da universidade medieval, e aborda tanto as doutrinas da revelação cristã (Trindade, Encarnação, Graça e os Sacramentos) quanto as esferas da moral e da política, no que se vale de Aristóteles, da filosofia clássica e do Direito romano. (SIGMUND, 2003, p. 712).

Revista de Direito Brasileira | São Paulo, SP | v. 16 | n. 7 | p. 96 - 114 | Jan./Abr. 2017 
humanas, é levada a forjar a imagem de uma Natureza caprichosa e contingente, em cujo interior somos meros joguetes. (CHAUI, 1995, p. 34).

A tirania religiosa e política, portanto, residia no medo e na esperança irracionais, alimentadas pela ignorância das pessoas sobre a verdade de Deus, da Natureza e delas próprias. Por isso é que o estudo da filosofia (lógica, física e metafísica), por exemplo, era considerado idolatria e blasfêmia.

Spinoza e seu racionalismo afirmam e demonstram que a totalidade do real é inteligível a qualquer pessoa e pode ser integralmente conhecida pelo intelecto, não havendo espaço para mistérios, milagres ou coisas ocultas. Além disso, a filosofia spinoziana afirmou, em oposição à estabilidade dos medos e das esperanças (a flutuação ou a mudança delas era perniciosa ao engessamento do ser) que a casta religiosa e política impunham, ser da natureza humana a inconstância dos medos e das esperanças (muda-se de deuses conforme mudam os temores e as esperanças).

O racionalismo spinoziano equivale, nesse tom, à libertação das causas da ignorância, o que fará desatar-se também dos medos e das esperanças viciadas pelos efeitos religiosos e políticos. Trata-se da capacidade libertadora da razão, alcançável por dois meios: a interpretação histórico-crítica da Bíblia, que reprime o poder supersticioso da religião e da teologia, e a correção do intelecto, ao efeito de que a força deste último subjugue a da imaginação.

Esse descortinar spinoziano para uma nova ideia da felicidade e da liberdade, inéditas no pensamento moderno, se funda em, pelo menos, seis preceitos básicos: (1) Deus e a Natureza são uma só e mesma coisa; (2) Deus não é um ser supremo, onisciente e onipotente que age movido por fins misteriosos, monarca do Universo e juiz dos homens; (3) o homem é livre não porque dotado de livre-arbítrio (até porque Spinoza não difere entre bem e mal, destacando a "perfeição" como mero modo de pensar), mas por fazer parte da Natureza e por possuir a força interna de pensar e agir livremente; (4) a religião é mera consolação às almas dos devotos e, como tal, uma intermediária interessada. A verdadeira ligação espiritual entre a consciência individual e a divindade dispensa o aparato de igrejas, cerimônias e teologias; (5) o poder político nãs nasce de um contrato social das individualidades, mas da força coletiva da massa reunida num só ato de decisão pelo qual institui a si mesma como sujeito político detentor de um poder civil e não subordinado ao poder religioso-teológico; e, (6) a teologia difere da política e da filosofia. Enquanto a última se constitui num saber livremente buscado pela razão humana, a primeira equivale a uma ausência de saber verdadeiro que pretende conseguir a obediência e a submissão das consciências a dogmas indemonstráveis, se constituindo, por isso, em um poder tirânico, não em conhecimento. (SPINOZA, 2009).

Com essas teses, a filosofia spinoziana se consubstancia numa ruptura entre a liberdade de pensamento, de expressão e de ação e a servidão ética, política e teológica. Noutras palavras, é responsável, já no Século XVII, por uma nova noção de sujeito de direitos, empoderado pelo conhecimento e sem as amarras da superstição e do medo apostólico. Corroborando, Marilena Chaui (1995, p. 12) vaticina:

[...] sua obra faz desabar os pilares que sustentam a superstição religiosa, a tirania política e a servidão ética. Ao fazê-lo, põe em questão as imagens tradicionais de Deus, da Natureza, do homem e da política que serviam de fundametno à religião, à teologia, à metafísica e aos valores ético-politicos da cultura judaico-cristã, isto é, da cultura ocidental. É o radicalismo da razão livre e da alegria de pensar sem submissão a qualquer poder constituído - seja este religioso, político, moral ou teórico - e a decisão de afastar tudo quanto nos cause medo e tristeza que torna Espinosa perigoso e odiado, para uns, mas também tão amado, para outros. 
No atinente específico do Direito, Spinoza insere-se na tradição moderna que afirma o Direito Natural, todavia, com uma peculiaridade: assume tanto o racional quanto o divino na fundamentação do Direito, graças à identificação da natureza com o próprio Deus.

Todos existem por direito supremo da natureza e conseqüentemente cada um faz, pelo direito supremo da natureza, o que decorre da necessidade de sua própria natureza; e assim cada um julga, pelo direito supremo da natureza o que é bom, o que é mau, ou consulta a sua utilidade segundo o seu engenho, se vinga, e se esforça por conservar aquilo que ama, e por destruir aquilo que odeia. Porque se os homens vivessem dirigidos pela razão, cada um possuiria o direito que lhe pertence, sem nenhum prejuízo para outrem. (SPINOZA, 2009, p. 37).

O excerto colacionado denuncia a concepção de Direito Natural que Spinoza defende: 1) a existência é decorrência de um Direito supremo da natureza; 2) o agir segue a necessidade da natureza de cada um; 3) o juízo sobre o bem e o mal é relativo à conservação do que interessa ao esforço de autopreservação; 4) o seguimento da razão é o critério para o reconhecimento do próprio Direito sem prejuízo de terceiros. É consequência desse raciocínio o entendimento de Spinoza acerca de Direito e instituição da natureza: unicamente as regras da natureza de cada indivíduo, regras segundo as quais concebemos qualquer ser como naturalmente determinado a existir e a agir de certa maneira.

Spinoza supera o tomismo porque não aceita a validade da lei divina sobre a vida humana, visto que (a lei divina) vige exclusivamente no âmbito religioso, sendo algo relevante também para a vida natural. Tratam-se, portanto, de âmbitos essencialmente separados e devem ser reconhecidos como tais. A lei divina, lei de Deus, lei dada por Deus, está, segundo Spinoza, posta nas Escrituras; não é complicada, não necessita intérprete, qualquer um pode pegar a Bíblia, lê-la e compreender por si o que diz a lei divina.

Para o spinozismo, não é preciso teologia para acessar a justeza, uma vez que não se necessita intérprete para acessar a Deus, sendo o bastante a leitura da Bíblia, que, não obstante as alegorias do momento histórico, diz coisas perfeitamente simples e compreensíveis a qualquer pessoa, ainda que de pouco estudo. $\mathrm{O}$ que emerge da Bíblia se resume, ao fim e ao cabo, no exemplo e na mensagem moral do Cristo; a teologia é que "vendeu" uma estrutura gigantesca, totalmente ilegítima, segundo Spinoza. A lei divina, então, serve unicamente para a vida do fiel, não possuindo relevância para o Direito e para a política.

Relativamente à lei humana - que não têm origem divina e experimenta uma variedade quase infinita, dado que cada comunidade tem uma diferença (multiculturalismo) -, tratar-se-ia de expressão necessária da vontade de quem detém a potestas. Se assim o é, tem lugar a indagação: o que torna válida, do ponto de vista da razão, uma lei positiva humana? Para Spinoza, a feição democrática e tolerante, sobretudo.

Com efeito, somente quando a lei positiva é construída no interior de uma prática política democrática ela realmente faz sentido de um ponto de vista racional. Em assim não sendo, ela é mero instrumento de violência. O poder representado pela lei positiva só é útil se corresponder a uma potência coletiva de toda a comunidade política, se tiver origem na própria multidão, no próprio povo. É por essa razão que a lei positiva tem de ser, no spinozismo, um instrumento institucional de uma democracia.

É exatamente por essa razão que Joaquín Herrera Flores (2009) vai afirmar que os Direitos Humanos, cujo ideal foi gestado no cenário racional de Spinoza, se assentam como produtos culturais, conformando uma tendência humana ancestral por construir e assegurar as condições sociais, políticas, econômicas e culturais que permitem aos seres humanos perseverar na luta pela dignidade. É o impulso vital que, em termos spinozianos, possibilita às pessoas manterem-se na luta por seguir sendo o que são: seres dotados de capacidade e potência para atuar por si mesmos. 
Resulta, de tudo, que, ao final do Trânsito à Modernidade, os Direitos Humanos se assentavam como produtos culturais que objetivavam assegurar condições específicas e características peculiares aptas a preservarem a dignidade dos seus agentes. De que modo eles migraram dessa situação sensível, forjada no Humanismo, para uma universalidade abstrata e racionalizada ao extremo? É o que se passa a examinar.

\section{A UNIVERSALIDADE ABSTRATA E RACIONAL DA DECLARAÇÃO UNIVERSAL DOS DIREITOS HUMANOS}

Antes de se analisar a linha evolutiva da internacionalização dos Direitos Humanos, forjada no critério universalista, impulsionada pela concepção da Organização das Nações Unidas e originada nos desdobramentos da Declaração Universal dos Direitos Humanos, importa passar os olhos nos movimentos imediatamente anteriores, haja vista que, em Direito Humanos, nada se explica desprezando a linha histórica do tempo.

A uma, o processo de positivação, que teve origem nos já examinados iusracionalismo e contratualismo e abordou os direitos de primeira geração, a saber, as liberdades (abstenções do Estado). De fato, a conjunção do estado de natureza e da sociedade sob o império do Contrato Social de Jean-Jacques Rousseau (2003) justificava o poder, cuja função soberana precípua era a criação do direito. Ademais, não se pode deixar de considerar o rompimento com as teorias jusnaturalistas e o advento, na França, do positivismo jurídico ${ }^{14}$. Do século XIX em diante, a positivação passa a ser regra geral, principalmente por meio da inscrição dos direitos fundamentais (Humanos) nos catálogos das Constituições, até em face do caráter de segurança que ostenta um rol escrito.

Doravante, esse processo determina o surgimento de um braço específico da ciência jurídica para o seu estudo, a teoria dos direitos fundamentais. Se é bem verdade que a mera inscrição de um direito num catálogo não lhe assegure garantia de efetividade, sem a positivação, simples ideias morais ou valores não deteriam sequer a possibilidade de serem exigidos, daí a sua importância destacada.

A duas, o processo de generalização dos Direitos Humanos, que partiu de uma grande contradição e perseguiu os direitos de segunda geração, de igualdade; paralelamente à afirmação da naturalidade dos direitos (comum a todos os humanos), praticava-se uma fruição seletiva dos mesmos, direcionada unicamente à burguesia. Essa caracterização histórica dos Direitos Humanos como gerais e abstratos, todavia, prática e veladamente seletivos, se protraiu no tempo, influenciando a produção do direito nos ordenamentos internos com esse mesmo vício.

Nas letras de Peces-Barba Martínez (1995, p. 161), a compreensão do teor racional dos Direitos Humanos e a sua capacidade de transcender à sua criação e às forças sociais que a sustentaram os converterão em ferramenta ética: a moralidade dos Direitos Humanos, vocacionados à eficácia social na busca da liberdade e da igualdade. Luis Prieto (1986-1987, p. 303), de seu turno, invoca o novo sentido da generalização dos Direitos Humanos:

Um conceito de direitos humanos menos abrangente e abstrato, mais permeável às necessidades do homem e da história, pode ser promovido por abordagens que, mesmo sem renunciar completamente com as noções de natureza e contrato, concebam os primeiros como táticas de emancipação.

\footnotetext{
14 Confira-se, por exemplo, que, na declaração francesa de 1789, o artigo $4^{\circ}$ estabelecia que o limite dos direitos só poderia ser determinado pela lei, ao passo que o artigo $6^{\circ}$ declarava que a lei constituía a expressão da vontade geral. Portanto, o início do processo de positivação é uma conexão fundamental entre a lei positivada e os Direitos Humanos (agora fundamentais, se pensada a corrente que considera a positivação como signo distintivo entre as duas conceituações).
} 
E eis que se chega, então, à linha evolutiva da internacionalização dos Direitos Humanos, inaugurada no período posterior à Segunda Guerra Mundial como resposta aos horrores produzidos durante o nazismo, que expôs o Estado como o grande violador de Direitos Humanos.

O processo de internacionalização dos Direitos Humanos se exterioriza, assim, por um sem número de tratados internacionais de proteção aos Direitos Humanos. Antes, porém, no período anterior à Segunda Guerra Mundial, instrumentos de direito humanitário ${ }^{15}$, o constitutivo da Liga das Nações e o da Organização Internacional do Trabalho forjaram esse processo. Antes disso, as obrigações internacionais oriundas de tratados, ainda que versassem Direitos Humanos, restringiam seus alcances aos Estados-partes das convenções.

Esse é o pano de fundo em que nasce a Organização das Nações Unidas, em 1945, incontinenti o fim da Segunda Grande Guerra. Importa registrar, entretanto, que sua concepção ocorrera três anos antes, na Declaração das Nações Unidas, de 12 de janeiro de 1942, ainda na fluência do conflito armado, oportunidade em que vinte e seis países se obrigaram pela obrigação de prosseguir a luta contra os países então representativos do Eixo Roma-Berlim-Tóquio.

A Carta das Nações Unidas, documento que formalmente deu origem à Organização, foi elaborada na data de 25 de abril a 26 de junho de 1945, na cidade de São Francisco, no estado da Califórnia, nos Estados Unidos da América. A Carta foi elaborada pelos representantes dos cinquenta países presentes à Conferência sobre Organização Internacional. Após a ratificação da Carta da ONU, em 24 de outubro de 1945, por seus cinco membros permanentes do Conselho de Segurança - a China, os Estados Unidos da América, a França, o Reino Unido, a ex-União Soviética - e pela maioria dos demais signatários, a Organização das Nações Unidas passou a oficialmente existir no plano jurídico e político. A Assembleia-Geral da ONU se reuniu pela primeira vez em 10 de janeiro de 1946, na cidade de Londres, no Reino Unido. Nessa reunião, foi decidido que a sede permanente da ONU seria nos Estados Unidos. Atualmente, além da sede central em Manhattan, nos Estados Unidos, a ONU possui sedes em Genebra (Suíça), Viena (Áustria), Nairóbi (Quênia), além de escritórios em outros países. (GRUBBA, 2015, p. 148).

Foi por meio da Declaração Universal dos Direitos Humanos, de 1948, que a Organização se lançou definitivamente à esfera de proteção desses direitos, valendo-se do critério universalista já tão citado neste texto.

A Declaração Universal dos Direitos Humanos (DUDH) é um documento marco na história dos direitos humanos. Elaborada por representantes de diferentes origens jurídicas e culturais de todas as regiões do mundo, a Declaração foi proclamada pela Assembleia Geral das Nações Unidas em Paris, em 10 de Dezembro de 1948, através da Resolução 217 A (III) da Assembleia Geral como uma norma comum a ser alcançada por todos os povos e nações. Ela estabelece, pela primeira vez, a proteção universal dos direitos humanos. (ORGANIZAÇÃO, 2016).

Sucede que, como anunciado, a crise por que passam os Direitos Humanos reside no afastamento do Humanismo do seu ideal, decorrente, na advocacia deste estudo, da obliterada aplicação (abstrata e racional) do critério universalista ${ }^{16}$. Escreveu-se, inclusive, alhures, que o

15 Thomas Buergenthal (1988, p. 190, tradução livre) assevera tratar-se do "[...] ramo dos Direitos Humanos que se aplica aos conflitos armados internacionais e, em determinadas circunstâncias, aos conflitos armados nacionais".

16 "Estamos diante de uma lógica bastante simplista que, contudo, tem consequências muito importantes, pois conduz a uma concepção "a priori” dos direitos humanos. Se estamos atentos, essa lógica nos faz pensar que temos

Revista de Direito Brasileira | São Paulo, SP | v. 16 | n. 7 | p. 96 - 114 | Jan./Abr. 2017 
surgimento e o desenvolvimento do Humanismo se constituíram no ponto nodal do processo histórico-jurídico de formação do ideal de Direitos Humanos. Se assim o é, cabe a pergunta: em que ponto do processo evolutivo dos Direitos Humanos se perdeu o Humanismo?

A resposta a essa indagação remonta ao início da era cristã: o Humanismo se perde a partir da justificação "secular" do universalismo dos Direitos Humanos, iniciado pela pregação da doutrina do homem incorruptível do apóstolo Paulo em suas Cartas. Noutros dizeres, decorre da projeção que Paulo de Tarso realiza, atribuindo as coisas boas e virtuosas a Deus e as más e iníquas aos homens, todavia, com a possibilidade da reconciliação, do perdão e da vida eterna.

No século $I^{\circ}$ da era cristã foi proclamado um progresso fabuloso. Vitória sobre a corrupção! Vitória sobre a morte! O eco ainda ressoa. Quem, com a audácia do gênio, construiu a ambiciosa teoria que libertava a humanidade de sua natureza humana e da morte? Paulo de Tarso, São Paulo. Ele anunciou ao mundo a grande nova: "A incorruptibilidade é a vida eterna". O mundo ficou definitivamente abalado. O combate contra a corrupção estava lançado. Ainda dura. (SUSINI, 2010, p. 159).

O universalismo, de efeito, nasce com Paulo, por meio da pregação de conversão dos maus, numa transposição ao outro-pecador (impuro, mas salvável pela vida eterna) da própria conversão operada em si, enquanto Saulo, na estrada de Damasco. O apóstolo de Tarso, único intelectualizado dentre os seguidores do Cristo e difusores do cristianismo primitivo, tinha a perfeita noção de que precisaria fazer da sua ação missionária um ato universalista.

Ainda que eu seja livre em relação a todos, eu me tornei o servidor de todos, a fim de ganhar o maior número possível. Com os judeus, fui como judeu, a fim de ganhar os judeus; com os que estão sob a lei, como sob a lei (ainda que eu mesmo não esteja sob a lei), a fim de ganhar aqueles que estão sob a lei; com os que estão sem lei, como sem lei (ainda que eu não esteja sem a lei de Deus, estando sob a lei de Cristo), a fim de ganhar aqueles que estão sem lei. Fui fraco com os fracos, a fim de ganhar os fracos. Tornei-me tudo para todos. (BÍBLIA SAGRADA, 2006, 1Cor. 9. 19 e ss.).

O fato é que o Humanismo, preocupado em separar a noção de vida como bemaventurança a ser alcançada numa vida futura e em pregar a valorização da vida quotidiana, prática, de atividades mundanas e até mesmo da entrega a algum prazer, inclusive reconhecendo fragilidades e demências, não consegue se coadunar com essa incorruptibilidade universalista da salvação dos iníquos pela vida eterna, lei última da reconciliação entre o pecador e Deus. Eis o busílis: se há superioridade das leis divinas, transcendentes das humanas, não há modo de implantar com sucesso e senso crítico um juízo de valorização do humano.

É por essa razão que, sendo a pregação pauliana a fundadora do universalismo, tido como o principal caractere dos Direitos Humanos, também não se consegue coadunar Humanismo e universalismo. O Humanismo que brota do Renascimento por mais que tenha informado o ideal de Direitos Humanos, jamais conseguiu ombrear com o universalismo. Essa impossibilidade, que está na gênese do critério universalista, faz com que a universalidade propalada pela Declaração Universal dos Direitos Humanos e pela própria Organização das Nações Unidas não atenda, com competência, alcance e eficácia, aos reclamos humanitários de forma efetivamente generalizada e equânime.

os direitos mesmo antes de ter as capacidades e as condições adequadas para poder exercê-los. Desse modo, as pessoas que lutam por eles acabam desencantadas, pois, apesar de nos dizerem que temos direitos, a imensa maioria da população mundial não pode exercê-los por falta de condições materiais para isso". (HERRERA FLORES, 2009, p. 27). 
Não são poucas, com efeito, as flechas direcionadas ao pretenso universalismo eurocêntrico ou ocidentalizado dos Direitos Humanos, disparadas pelos relativistas culturais. Quem defende a universalidade dos Direitos Humanos a fundamenta na dignidade humana originária, na qualidade de valor intrínseco à condição humana. Fala-se, aqui, na defesa de um "mínimo ético irredutível". Os relativistas objetam que a noção de direitos está relacionada ao sistema político, econômico, cultural, social e moral vigente em determinada sociedade. Cada cultura possuiria seu próprio discurso acerca dos direitos fundamentais, que está relacionado às específicas circunstâncias culturais e históricas de cada sociedade. Não se concebe, aqui, moral universal, porquanto a história do mundo é a história de uma pluralidade de culturas.

A acusação dos relativistas, anota Flávia Piovesan (2015, p. 53), é que os universalistas intentam a dominação hegemônica da cultura eurocêntrica ocidental, ao passo que os universalistas, em contra-ataque, imputam aos opositores a pecha de, em nome do respeito a pretensas diferenças culturais, acobertarem graves violações a direitos humanos. Antonio Enrique Pérez-Luño (2002, p. 36, tradução livre), no ponto, considera:

[...] enquanto para a crítica filosófica a universalidade é impugnada por seu caráter ideal e abstrato, para a crítica política a nocividade decorre da tentativa de suavizar e ignorar as diferentes tradições políticas das diversas culturas, tanto assim que a crítica jurídica já denunciava a sua impossibilidade, considerando a inexistência de um marco socioeconômico comum apto a satisfazer todos os direitos humanos numa escala planetária.

É bem verdade, noutro giro, que não há como se opor ao caráter universal desses direitos e à obrigação legal dos Estados de promover e respeitar os direitos e as liberdades fundamentais. O modo como os entes estatais tratam as pessoas sob o seu jugo não é mais matéria reservada, em face da submissão dos primeiros às Cortes dos organismos regionais de proteção dos Direitos Humanos, como a Corte Interamericana de Direitos Humanos e o Tribunal Europeu de Direitos Humanos, por exemplo.

De fato, tanto há razão nos universalistas, como nos relativistas. A dos primeiros reside no fato de que, em os Direitos Humanos não sendo universais, se esvaziam em conteúdo e importância. A dos segundos vem no sentido de não ser imposta uma visão ocidentalizada de direitos a povos de credos e culturas milenares diversas e bem peculiares.

Esse paradoxo é clarividente na existência da Declaração Universal dos Direitos do Homem, de 1948, e, concomitantemente, na da Declaração dos Direitos Humanos no Islão, aprovada em 1990. José Carlos Vieira de Andrade (2012, p. 28-29) suscita, no ponto, que esta última só foi assinada, no Cairo, em 1994, no âmbito da Liga Árabe, passando a se denominar Carta Árabe dos Direitos Humanos, que teve uma segunda versão aprovada em 2004 e que se encontra em vigor desde 2008, malgrado criticada por iniciar pela afirmação do direito dos povos à autodeterminação e pela condenação do racismo e do sionismo. Na época, prossegue o autor, a Alta-Comissária para os Direitos Humanos da ONU considerou o texto incompatível com as normas internacionais no que atine aos direitos das mulheres e na continuidade da consideração do sionismo como uma espécie de racismo.

De efeito, ou a Declaração de 1948 é "universal” e os Direitos Humanos compreendem ocidentais e orientais, ou, realmente, cede aos relativismos culturais. Se há razão - e, portanto, vicissitudes - em ambos os argumentos, qual a solução? É possível atualizar o critério universalista abstrato e coaduna-lo com o relativismo cultural? Mais: há como se repatriar o Humanismo para o ideal universalista? As respostas, afirmativas, às primeiras e segundas questões passa pelo sim da terceira. Tudo inicia pela reinserção do Humanismo.

No momento presente, caracterizado pela "sociedade do descarte" a que alude Zygmunt Bauman (2011), pela difusão desmedida da lógica da destruição e da violência e em cujo âmbito a pessoa já não possui valor (vide as medidas de "proteção" adotadas nos países europeus para 
conter o fluxo migratório do Médio Oriente), é imperiosa a reconstrução da universalidade dos Direitos Humanos.

É intempestivo, portanto, o resgate do valor da pessoa, do sentimento de cuidado entendido, na intelecção de Leonardo Boff (2008, p. 91), como “[...] desvelo, solicitude, diligência, zelo, atenção, bom trato. [...] o cuidado somente surge quando a existência de alguém tem importância para mim" - para com todos os seres humanos. O atual estágio da humanidade, de difusão do conhecimento, da ciência, da tecnologia e, mesmo, de uma espiritualidade racional, não permite mais que se atrele a compreensão do ideal de Direitos Humanos a uma universalização divina obliterada que mais serviu à globalização de uma crença religiosa do que propriamente à generalização do bem.

A compreensão atual de Humanismo que se deseja reconhece distintas manifestações de humanidades, tanto no Oriente quanto no Ocidente, incluindo diferentes perspectivas do humano em autênticos fluxos globais de interação, não mais verticalizados. Aliás, o ideal de humanismo sempre galgou passos pela potencialização de conexões horizontais, num esforço humano para manejar o mundo dos humanos. É inexorável, portanto, que essa reincorporação do Humanismo se dê também em observância de um avanço necessário e salutar que decorre da influência do processo de globalização e do Transnacionalismo consequente, que faz irromper uma quinta linha evolutiva dos direitos, qual seja, a da transnacionalização, consistente na inclusão do conteúdo dos Direitos Humanos nos espaços de direito global e na utilização dos instrumentos deste último, mormente a circulação de modelos jurídicos.

No ponto, é relevante destacar, ainda, o enfoque dado por Rodotà (2012, p. 184). Ao considerar a "omnização do humano", o faz sob o prisma de uma das principais características do transnacionalismo: a facticidade caso a caso. Através dela, adverte, se abriu uma via alternativa em busca da igualdade, expurgando a institucionalização da discriminação. Um caminho onde a liberdade encontra a igualdade. Daí a necessidade de se pensar de pessoa para pessoa. Essa é a nova antropologia, que não aprisiona o sujeito, mas fornece caminhos de acesso. É essa, portanto, a inversão de lógica que se propugna na aplicação dos Direitos Humanos: a passagem do homem abstrato (universalidade abstrata) para o homem concreto (universalidade sensível), valorizando o Humanismo.

Trata-se de uma relação dialógica que contempla a atualização com o cenário transnacional, com a circulação de modelos jurídicos e com a exigibilidade dos Direitos Humanos num conceito integral, para além dos Estados, derrubando-se fronteiras físicas e geopolíticas. Já é hora, de fato, de se compreender que os Estados não são mais os únicos dotados de capacidade e vontade para com os Direitos Humanos, em face de fenômenos como a globalização e o transnacionalismo, os quais, a reboque, trouxeram a criação e a aplicação de normas em espaços de não-Direito ${ }^{17}$.

É mister observar que a lógica monocêntrica em que apenas Estados e organismos internacionais produziam um Direito abstrato, impessoal, cogente, de direito público e baseado na vigência territorial dá lugar, em amplitude cada vez maior, a um espaço multinível e policêntrico no qual entidades privadas ditam regras concretas, pessoais e específicas, via de regra, consensuais, de Direito privado e vigentes em qualquer lugar do orbe.

A busílis, portanto, é de que os Direitos Humanos se constituam no mínimo ético dessa nova ordem. Entretanto, como isso é possível, considerando a universalidade e o relativismo cultural? É hora, pois, de responder àquela segunda indagação, alhures formulada nesta seção, que perquiria a possibilidade de concílio entre universalismo e relativismo cultural. Sim, há

17 Nas palavras de Paolo Grossi (2007, p. 78), “[...] a lei vazia era uma espécie de sapientíssima forma dentro da qual um legislador onisciente, infalível, onipotente, poderia hospedar qualquer conteúdo que desejasse. O ordenamento jurídico, resumido em um grande esqueleto legislativo, admitia um só cordão umbilical, aquele com o poder, o único de onde pudesse retirar vitalidade, nutrimento, efetividade, não reconhecendo nenhum outro que representasse a complexidade da sociedade".

Revista de Direito Brasileira | São Paulo, SP | v. 16 | n. 7 | p. 96 - 114 | Jan./Abr. 2017 
chance. De que modo? Abandonando a preguiça interpretativa de um imaginário simplificado e reduzido de Direitos Humanos que só enxerga o estereótipo linear e eurocêntrico que anestesia seu alcance e sua efetividade. Observar as diferenças culturais sem, contudo, desprestigiar a universalidade dos Direitos Humanos, para o que cunhou a expressão "direitos relativamente universais". Parece se encontrar aqui um ponto de equilíbrio da controvérsia:

Meu principal objetivo é explicar e defender os direitos humanos como direitos universais. Eu não sustento, contudo, que esses direitos sejam estáticos, imodificáveis ou absolutos; qualquer elenco ou concepção de direitos humanos e a ideia de direitos humanos por si mesma - apresenta uma especificidade cultural e contingente. [...] Este livro demonstra que a contingência histórica e a particularidade de direitos humanos é completamente compatível com a concepção de direitos humanos como direitos morais universais, que não nos permite aceitar fortes reivindicações do relativismo cultural. (DONNELY, 1989, p. 124, tradução livre).

É o que David Sánchez Rubio (2014, p. 49) vai chamar de "proposta intercultural e complexa de direitos humanos", propugnando a ênfase a uma convocação e a uma consciência de uma cultura e sensibilidade sócio-popular de direitos humanos que não esteja baseada numa única expressão ou forma de vida humana. Há nítida consideração, portanto, dos sujeitos sociais, da sua capacidade de relacionalidade, dos entornos e espaços temporais em que se situam, suas espiritualidades a partir de lógicas de dominação imperialista ou de emancipação e libertação que deve ser incorporada na análise jurídica. Não se trata de denunciar o problema da concepção demasiado estreita e simplista, mas incorporar o elemento cultural e relacionado à universalidade do mesmo.

Perceba-se, a esta altura, que o presente ensaio não busca desconsiderar os avanços históricos obtidos a partir da atuação da Organização das Nações Unidas, que são incontroversos, notadamente sob o ponto de vista humanitário. Igual modo, não se está a descortinar uma descoberta ou uma revolução em termos de Direitos Humanos. Essa visão dialógica da universalidade, que contempla, de forma concomitante, aspectos universais (necessários), multiculturais e plurais (igualmente pertinentes) se constitui, antes, numa virada interpretativa que atualiza o ideal de Direitos Humanos (reinclusão do Humanismo) e permite - sem traumas a aplicação destes últimos em espaços geopolíticos fluídos, sejam ocidentais, sejam orientais, com respeito às especificidades multiculturais de cada sociedade. Afigura-se de primordial importância, nessa virada que se defende, que todas as culturas sejam ouvidas e tenham voz, no ensejo de uma congregação realmente polifônica e universal. É nessa linha argumentativa que Antonio Enrique Pérez-Luño (2002, p. 38) sustenta, frente aos enfoques atuais humanitários, a necessidade de uma fundamentação dos sistemas constitucionais e de Direitos Humanos baseado num novo ethos universal, síntese de valores multinacionais e multiculturais, que torne possível a comunicação intersubjetiva, a solidariedade e a paz.

Nessa nova lógica aplicativa, Boaventura de Souza Santos (1997, p. 21-23), por exemplo, preconiza uma concepção multicultural de Direitos Humanos, produto do diálogo entre as culturas, a compor um multiculturalismo emancipatório, processo que divide em cinco premissas: 1) superação da discussão entre universalistas e relativistas, 2) transformação cosmopolita, 3) todas as culturas são incompletas e problemáticas nas suas concepções de dignidade humana, 4) todas as culturas têm versões diferentes de dignidade humana, algumas mais amplas do que outras, algumas com um círculo de reciprocidade mais largo do que outras, algumas mais abertas a outras culturas do que outras, e 5) todas as culturas tendem a distribuir as pessoas e os grupos sociais entre dois princípios competitivos de pertença hierárquica: o princípio da igualdade, que opera através de hierarquias entre unidades homogêneas (entre estratos socioeconômicos, entre cidadãos e estrangeiros), e o princípio da diferença, que se concretiza por 
meio da hierarquia entre identidades e diferenças consideradas únicas (entre etnias ou raças, entre sexos, entre religiões, entre orientações sexuais)).

A melhor compreensão desse novo teor da universalidade, todavia, no entender deste ensaio, vem de Joaquín Herrera Flores (2009, p. 19), por meio de sua "teoria crítica dos Direitos Humanos", contextualizada em práticas sociais emancipatórias, sendo os direitos vistos como "resultados provisórios de lutas sociais por dignidade":

a universalidade dos direitos somente pode ser definida em função da seguinte variável: o fortalecimento de indivíduos, grupos e organizações na hora de construir um marco de ação que permita a todos e a todas criar as condições que garantam de um modo igualitário o acesso aos bens materiais e imateriais que fazem com que a vida seja digna de ser vivida. Por essa razão, os direitos humanos não são categorias prévias à ação política ou às práticas econômicas. A luta pela dignidade humana é a razão e a consequência da luta pela democracia e pela justiça. Não estamos diante de privilégios, meras declarações de boas intenções ou postulados metafísicos que exponham uma definição da natureza humana isolada das situações vitais. Pelo contrário, os direitos humanos constituem a afirmação da luta do ser humano para ver cumpridos seus desejos e necessidades nos contextos vitais em que está situado.

É precisamente essa nova dimensão universalista dos Direitos Humanos que deve nortear a aplicação desses últimos no momento presente, atendendo aos reclamos humanitários da atualidade (situações como a das novas correntes migratórias do Médio Oriente à Europa, por exemplo, de forma a demonstrar que o erguimento de muros ou cercas não dissolve o vínculo antropológico comum de europeus e sírios). Igual modo, a nova composição do ideal de Direitos Humanos (atualização do universalismo a partir da reinclusão do Humanismo) e essa nova lógica de aplicação (multicultural) já deve ser empregada no fechamento do que, segundo Antonio Cassese (2012, p. 171), se constitui na maior fábrica de violações aos Direitos Humanos da atualidade: a prisão da base naval norte-americana de Guantánamo, em Cuba. Forjada sobre a tortura e toda a sorte de tratamentos desumanos e degradantes, a detenção indeterminada, inclusive de crianças e adolescentes, ofende tudo o quanto se estratificou, ao longo da história, como dignidade, em que cultura for ${ }^{18}$. O mesmo raciocínio se poderia empregar, diga-se, aos ataques a civis, escolas e hospitais na Faixa de Gaza ou aos bombardeios russos, americanos e franceses às populações também civis da Síria, a pretexto de retaliação à organização paramilitar "Estado Islâmico" pelos atentados perpetrados em Paris, no ano de 2015, ou em Bruxelas, em 2016, cujas autorias foram reclamadas.

Afigura-se absolutamente inexorável o que Paulo Márcio Cruz (2008, p. 234) denomina "up grade civilizatório", consistente no abandono da visão solipsista dos Direitos Humanos, que observa a pessoa e suas inter-retroações como objeto, para uma lógica na qual o Humanismo seja o efetivo parâmetro em que a proteção ao fenômeno vida se torna fundamental. Sem o conviver, pouco ou nada se sente daquilo que, coletivamente, se almeja. Essa atualização, vital à manutenção da efetividade, da própria existência dos Direitos Humanos e, mesmo, condição da solidariedade e da paz, é trabalho afanoso, diário e já tardio, que compete não apenas aos operadores do direito, diz respeito a cada pessoa enquanto componente da imensa, diversa e plural família humana.

\section{CONCLUSÃO}

18 Ver, a respeito, o Informe da Comissão Interamericana de Direitos Humanos denominado Hacia el cierre de Guantánamo (COMISSÃO INTERAMERICANA DE DIREITOS HUMANOS, 2015).

Revista de Direito Brasileira | São Paulo, SP | v. 16 | n. 7 | p. 96 - 114 | Jan./Abr. 2017 
A insubsistência do ideal de Direitos Humanos desprovido dos ideais de Humanismo e forjada numa universalidade abstrata e excessivamente racional é, como se viu, manifesta. Para além disso, a lógica aplicativa que se digladia entre o universalismo (abstrato) das normas de Direitos Humanos e o relativismo cultural perpetua um debate intrinsecamente falso, cujos conceitos polares são igualmente prejudiciais para uma concepção emancipatória dos Direitos Humanos, a ponto de pôr em cheque a própria existência desses últimos.

Essa anacronia perniciosa é a responsável pelo discurso de inocuidade que, nos últimos tempos, se associou aos Direitos Humanos, reduzindo-o, não raro, a puras e simples subvenções e ajudas humanitárias, ao passo que deveria reconhecer as realidades históricas e fomentar o despertar de direitos e garantias, através de ações virtuosas. Esse foi o cenário que serviu de problema de pesquisa ao presente estudo, desde já se podendo afirmar que as hipóteses lançadas no introito foram confirmadas.

A solução propugnada está, portanto, na reconstrução do critério universalista dos Direitos Humanos a partir da reinserção do Humanismo, encaminhamento que induz, a tiracolo, a solução de outra celeuma histórica e reticente: o (falacioso) embate entre universalismo e relativismo das normas de Direitos Humanos.

A universalidade rediviva dos Direitos Humanos projeta a virada necessária para uma concepção crítica, emancipadora, multicultural e cosmopolita desses últimos, que observa em cada cultura das infindáveis existentes no orbe suas diferenças de concepções de dignidade humana (nem todas a concebem em termos de Direitos Humanos), suas incompletudes e problemas nessas diversas concepções de dignidade (debilidade que provém do próprio pluralismo), suas versões diferentes da dignidade, algumas mais amplas do que outras, algumas com um círculo de reciprocidade mais largo do que outras, algumas mais abertas a outras culturas do que outras.

Em suma, o Humanismo nutrindo a universalidade sensível e atualizada permite a consecução de um sistema de Direitos Humanos baseado num novo sentimento universal, síntese de valores multinacionais e multiculturais, que torna possível a comunicação intersubjetiva, a solidariedade e a paz.

O momento presente se caracteriza por um sem número de movimentos - pessoais e estatais - que não apenas não compreendem a diferença alheia - étnica, cultural, religiosa -, como a abominam e a condenam, em julgamentos açodados. É contra essas indignidades que os Direitos Humanos, a partir de seu critério universal redivivo, precisa fazer frente.

E se, de fato, a Humanidade se encontra num novo trânsito, agora à pós-Modernidade, é assente de dúvidas que ao Humanismo reinserido na universalidade do ideal de Direitos Humanos e à concepção multicultural e plúrima desses últimos caberá o protagonismo no diálogo da mudança. Mudança que não acontecerá de cima para baixo, não funcionará como imposição legal ou estatal; será dependente, isto, sim, do agir de cada ser humano para com o Outro, dando origem a uma virtuosa cadeia de tolerância e acolhimento.

Só dessa forma a Humanidade conseguirá, através dos Direitos Humanos, responder aos reclamos da pós-Modernidade, do pluralismo e do multiculturalismo.

\section{REFERÊNCIAS}

ANDRADE, José Carlos Vieira de. Os direitos fundamentais na Constituição Portuguesa de 1976. 5. ed. Coimbra: Almedina, 2012.

BAUMAN, Zygmunt. A ética é possível num mundo de consumidores? Tradução: Alexandre Werneck. Rio de Janeiro. Zahar, 2011.

BIBLIA SAGRADA. Tradução da CNBB. 4. ed. rev. São Paulo: Editora Canção Nova, 2006. 
BOBBIO, Norberto. A era dos direitos. Tradução: Carlos Nelson Coutinho. Rio de Janeiro: Elsevier, 2004.

BOFF, Leonardo. Saber cuidar: ética do humano, compaixão pela terra. 15. ed. Petrópolis, (RJ): Vozes, 2008.

BUERGENTHAL, Thomas. International human rights. Minnesota: West Publishing, 1988.

CASSESE, Antonio. I diritti umani oggi. Roma-Bari: Laterza, 2012.

CHAUI, Marilena. Espinosa: uma filosofia da liberdade. São Paulo: Moderna, 1995.

COMISSÃO INTERAMERICANA DE DIREITOS HUMANOS. Hacia el cierre de Guantánamo. Disponível em: <http://www.oas.org/es/cidh/informes/pdfs/Hacia-cierreGuantanamo.pdf>. Acesso em: 10 de agosto de 2015.

CRUZ, Paulo Márcio. Democracia e pós-modernidade. In VALLE, Juliano Keller do; MARCELLINO JÚNIOR, Júlio César. Reflexões da pós-modernidade: estado, direito e constituição. Florianópolis: Conceito Editorial, 2008.

DONNELY, Jack. Universal human rights in theory and practice. Ithaca (NY): Cornell University Press, 1989.

GARCIA, Marcos Leite. A contribuição de Christian Thomasius ao processo de formação do ideal dos direitos fundamentais. Revista Novos Estudos Jurídicos. Itajaí, v. 10, n. 2, 2005, p. 417450 .

GRUBBA, Leilane Serratine. O problema do essencialismo no Direito: inerentismo e universalismo como pressupostos das teorias que sustentam o discurso das Nações Unidas sobre os direitos humanos. 2015. 346 f. Tese (Doutorado) - Universidade Federal de Santa Catarina, Florianópolis, 2015.

HABERMAS, Jürgen. Fundamentos pré-políticos do estado de direito democrático. In:

SCHÜLLER, Florian (Org.). Dialética da Secularização: sobre razão e religião. Tradução:

Alfred J. Keller. Aparecida, (SP): Ideias \& Letras, 2007, p. 23-57.

HERRERA FLORES, Joaquín. A (Re)invenção dos Direitos Humanos. Tradução: Carlos Roberto Diogo Garcia et. al. Florianópolis: Fundação Boiteux, 2009

Teoria Crítica dos Direitos Humanos: os direitos humanos como produtos culturais. Rio de Janeiro: Lumen Juris, 2009.

JAPIASSÚ, Hilton; MARCONDES, Danilo. Dicionário básico de filosofia. 3. ed. Rio de Janeiro: Jorge Zahar, 1996.

KUHN, Thomas. S. A estrutura das revoluções científicas. São Paulo: Perspectiva, 1991.

MORIN, Edgar. $O$ método 5: humanidade da humanidade - a identidade humana. 4. ed. Porto Alegre: Sulina, 2007. 
NOGARE, Pedro Dalle. Humanismos e anti-humanismos: introdução à antropologia filosófica. 13. ed. Petrópolis, RJ: Vozes, 1994.

ORGANIZAÇÃO DAS NAÇÕES UNIDAS. Declaração Universal dos Direitos Humanos. 1948. Disponível em: <http://www.dudh.org.br/wp-content/uploads/2014/12/dudh.pdf>. Acesso em: 14 mar. 2016.

. Documentos e publicações das Nações Unidas. 2016. Disponível em:

<https://nacoesunidas.org/docs/>. Acesso em: 14 mar. 2016.

PASOLD, Cesar Luiz. Metodologia da pesquisa jurídica: teoria e prática. 12. ed. São Paulo: Conceito Editorial, 2011.

PECES-BARBA MARTÍNEZ, Gregorio. Curso de derechos fundamentales: teoría general. Madrid: Universidad Carlos III de Madrid, 1995.

Lecciones de Derechos Fundamentales. Madrid: Dykinson, 2005.

PÉREZ-LUÑO, Antonio Enrique. Delimitación conceptual de los derechos humanos. In: PÉREZ-LUÑO, Antonio Enrique et al. Los derechos humanos: Significación, estatuto jurídico y sistema. Sevilla: Publicaciones Universidad de Sevilla, 1979.

. Serie de teoría jurídica y filosofía del derecho n. 23. Bogotá: Universidad Externado de Colombia, 2002.

PIOVESAN, Flávia. Direitos Humanos e Justiça Internacional. 6 ed. São Paulo: Saraiva, 2015.

Prefácio. In: FLORES, Joaquín Herrera. A (Re)invenção dos Direitos Humanos.

Tradução: Carlos Roberto Diogo Garcia et. al. Florianópolis: Fundação Boiteux, 2009, p. 13-16.

PRIETO, Luis. Ideología liberal y fundamentación iusnaturalista de los derechos humanos. Observaciones críticas, Anuário de Derechos Humanos. Madrid, n. 4, 1986-1987.

RODOTÀ, Stefano. Il diritto di avere diritti. Roma-Bari: Laterza, 2012.

ROUSSEAU, Jean-Jacques. O Contrato Social. São Paulo: Editora Martins Fontes, 2003.

RUBIO, David Sánchez. Encantos e desencantos dos direitos humanos: de emancipações, libertações e dominações. Tradução: Ivone Fernandes Morcilho Lixa e Helena Henkin. Porto Alegre: Livraria do Advogado Editora, 2014.

. Fazendo e desfazendo os direitos humanos. Tradução: Clóvis Gorczevski. Santa Cruz do Sul (RS): UNISC, 2010.

RUSEN, Jorn; KOZLAREK, Oliver. Humanismo en la era de la globalizacion. Desafios y perspecovas. Buenos Aires: Biblos, 2009.

SABORIT, Ignasi Terradas. Religiosidade na Revolução Francesa. Rio de Janeiro: Centro Edelstein de Pesquisas Sociais, 2009. 
SIGMUND, Paul E. Tomismo. In: CANTO-SPERBER, Monique (Org.). Dicionário de ética e filosofia moral. Tradução: Maria Vitória Kessler. São Leopoldo (RS): Editora Unisinos, 2003, v. 2.

SOUZA SANTOS, Boaventura de. Por uma concepção multicultural de direitos humanos. Revista Crítica de Ciências Sociais, Coimbra, n. 48, 1997, p. 11-32.

SPINOZA, Benedictus de. Ética. Belo Horizonte: Autêntica Editora, 2009.

SUSINI, Marie-Laure. Elogio da corrupção: os incorruptíveis e seus corruptos. Tradução: Procópio Abreu. Rio de Janeiro: Companhia de Freud, 2010.

TAYLOR, Charles. A ética da autenticidade. Lisboa: Edições 70, 2009. 